\title{
DIFFERENCES BETWEEN PORTION, INTAKE FRUIT AND VEGETABLE ON PACKED AND SCHOOL LUNCH TO RECOMMENDED THE BALANCED NUTRITION GUIDELINES IN SDIT THARIQ BIN ZIYAD.
}

\author{
Anggie Maramis Sarahita, Irfanny Anwar \\ Jurusan Gizi Poltekkes Kemenkes Jakarta II \\ Jln. Hang Jebat III Blok F3 Kebayoran Baru DKI Jakarta, Kode Pos 12120
}

Email: fanny_afif@yahoo.com

\begin{abstract}
Elementary Islamic Primary School (SDIT) Thariq Bin Ziyad is located in the residential area of Pondok Hijau Permai-Bekasi Timur is an Islamic elementary school that has the concept of full day school, where all students spend about 7 hours in school on Monday to Friday. At lunch time students are required to bring lunch from home or attend catering provided by the school. Based on preliminary test results found not that all students bring lunch contain vegetables and fruit or not suitable for the needs of primary school children. The purpose of this study was to differences portion and intake fruit and vegetable on Packed Meal and School lunch to Recommended Balanced Nutrition Guidelines In SDIT Thariq Bin Ziyad.This research uses food weighing method and interview. The sample of this research is students on grade 3 and 4 who bring food for lunch or catering food, amounted to 72 people. Analysis of univariate and bivariate data using Independent Test T-Test. The results showed that there was a difference between vegetable and fruit portion at Packed and School lunch, there was difference of vegetable intake on Packed and school lunch, and there was no difference between fruit intake at Packed and School lunch
\end{abstract}

Keyword: Packed and school lunch, portion fruit and vegetable, intake fruit and vegetable, recommended balanced nutrition guidelines

\section{PERBEDAAN ANTARA BESAR PORSI, ASUPAN SAYUR DAN BUAH MAKANAN BEKAL DAN MAKANAN KATERING TERHADAP ANJURAN PEDOMAN GIZI SEIMBANG DI SDIT THARIQ BIN ZIYAD}

\begin{abstract}
ABSTRAK
Sekolah Dasar Islam Terpadu (SDIT) Thariq Bin Ziyad di Bekasi Timur, merupakan sekolah dengan konsep "full day school" dimana siswa berada di sekolah selama 7 jam sehari mulai hari senin sampai jumat. Siswa dapat membawa bekal makan siang dari rumah ataupun berlangganan makan pada katering sekolah. Hasil observasi awal ditemukan dalam makanan bekal maupun makanan katering tidak selalu tersedia sayur dan buah. Kalaupun ada jumlahnya tidak sesuai kebutuhan. Tujuan dari penelitian ini adalah untuk mengetahui perbedaan besar porsi serta asupan sayur dan buah pada makanan bekal dan makanan katering terhadap anjuran Pedoman Gizi Seimbang Di SDIT Thariq Bin Ziyad. Penelitian ini menggunakan metode food weighing dan wawancara. Sampel penelitian sejumlah 72 orang murid kelas 3 dan 4 yang membawa makanan bekal ataupun makanan katering. Data dianalisis secara univariat dan bivariat dengan menggunakan Uji Independent Sampel T-Test. Hasil penelitian menunjukkan, ada perbedaan antara besar porsi sayur dan buah pada makanan bekal dan makanan katering, ada perbedaan asupan sayur pada makanan bekal dan makanan katering, serta tidak ada perbedaan antara asupan buah pada makanan bekal dan katering.
\end{abstract}

Kata Kunci: Makanan bekal dan makanan katering, besar porsi dan asupan sayur dan buah, Pedoman Gizi Seimbang 


\section{PENDAHULUAN}

Dalam Pedoman Gizi Seimbang (PGS) 2014 disebutkan bahwa $63.3 \%$ anak > 10 tahun tidak mengkonsumsi sayuran, dan $62.1 \%$ tidak mengkonsumsi buah-buahan Jumlah sayur dan buah yang dianjurkan adalah 300$400 \mathrm{~g}$ perorang perhari bagi anak balita dan anak usia sekolah, dianjurkan konsumsi sayur sebanyak \pm 200 - 250 gram perorang perhari, sedangkan untuk konsumsi buah dianjurkan \pm 100 -150 gram buah perorang perhari (1). Sekalipun ada ketentuan besar porsi dalam PGS namun masih belum terpenuhi. Hasil Riset Kesehatan Dasar (Riskesdas) 2013 menunjukkan bahwa penduduk berumur $\geq 10$ tahun yang kurang mengonsumsi buah dan sayur di DKI Jakarta adalah 95\% (2)

Program penyelenggaraan makanan untuk anak usia sekolah di Indonesia sudah mulai dilakukan terutama di sekolah dengan jumlah jam belajar yang lebih panjang. Dalam penelitian pada siswa SD di Kabupaten Bogor Jawa Barat ditemukan rata-rata asupan serat seluruh siswa masih rendah yaitu sekitar 18\% dari angka yang dianjurkan. Asupan serat siswa yang rendah terlihat dari kesukaan siswa terhadap jenis buah dan sayuran yang rendah (3). Penelitian yang dilakukan di Panti Asuhan Denpasar, rata-rata sampel mengkomsumsi sayuran dengan frekuensi 2-4 kali dalam seminggu dan mengkonsumsi buah-buahan dengan frekuensi 1-2 kali seminggu (4).

Sekolah Dasar Islam Terpadu (SDIT) Thariq Bin Ziyad yang berlokasi di daerah Perumahan Pondok Hijau Permai Bekasi Timur merupakan Sekolah Dasar Islam yang memiliki konsep pembelajaran sehari penuh, dimana seluruh murid menghabiskan waktu \pm 7 jam di sekolah pada hari senin sampai dengan jumat. Pada waktu makan siang siswa diwajibkan untuk makan disekolah, dapat dengan membawa bekal dari rumah ataupun mengikuti katering sekolah. Dari observasi awal ditemukan bahwa baik siswa yang membawa makanan bekal maupun mendapat makanan katering tidak semua mengkonsumsi sayur dan buah, kalaupun ada porsinya belum memenuhi syarat kebutuhan sesuai anjuran Pedoman Gizi seimbang. Perumusan masalah adalah bagaimana perbedaan besar porsi serta asupan sayur dan buah pada makanan bekal dan makanan katering terhadap anjuran Pedoman Gizi Seimbang Di SDIT Thariq Bin Ziyad. Penelitian ini bertujuan untuk mengetahui perbedaan besar porsi serta asupan sayur dan buah pada makanan bekal dan makanan katering terhadap anjuran Pedoman Gizi Seimbang Di SDIT Thariq Bin Ziyad.

Hasil penelitian diharapkan bermanfaat bagi murid sekolah dan orang tua, bagi pihak sekolah dan bagi pihak katering dalam hal memperoleh informasi tentang besar porsi sayur dan buah serta asupannya sesuai dengan kebutuhan anak.

\section{METODE PENELITIAN}

Penelitian dilakukan di Sekolah Dasar Islam Terpadu (SDIT) Thariq Bin Ziyad Bekasi pada bulan Januari 2017. Desain penelitian cross sectional. Populasi adalah seluruh siswa-siswi kelas 3 dan 4, jumlah sampel 72 orang. Subjek dipilih secara purposive, dengan kriteria inklusi siswa yang makan siang di sekolah baik dari makanan bekal maupun makanan katering, bersedia menjadi responden penelitian dan hadir saat penelitian berlangsung. Kriteria Eksklusi adalah siswa yang sedang sakit dan yang mengalami dissability. Data primer meliputi karakteristik subjek, pendidikan dan pekerjaan ibu, pengetahuan gizi (subjek dan ibu) diperoleh dari wawancara dengan kuesioner.

Definisi operasional terdiri dari jenis kelamin, pengetahuan gizi anak, pengetahuan gizi ibu, pendidikan ibu, pekerjaan ibu, makanan bekal, makanan katering, besar porsi sayur dan buah serta asupan sayur dan buah.

Hasil penelitian dikatagorikan baik, bila persentase $76 \%-100 \%$, cukup bila 
persentase $56 \%$ - 75\%, kurang bila persentase $<55 \%$.

Data besar porsi sayur dan buah yang dihidangkan serta sisa yang tidak dimakan, diukur dengan metode penimbangan (food weighing) menggunakan timbangan digital ketelitian 1 gram. Hasil penimbangan dibandingkan dengan Pedoman Gizi Seimbang (PGS) 2014. Besar porsi dan asupan sayur dikatakan baik bila $\geq 75$ gr, besar porsi dan asupan buah dikatakan baik bila $\geq 50$ gr.

Analisis statistik yang dilakukan adalah analisis deskriptif menggunakan piranti lunak meliputi analisis univariat dan analisis bivariat ( $\mathrm{T}$ Test) untuk melihat perbedaan konsumsi buah dan sayur pada makanan bekal dan makanan katering.

\section{HASIL DAN PEMBAHASAN}

Dari karakteristik subjek dapat dilihat bahwa subjek perempuan lebih banyak yang membawa makanan bekal dibandingkan dengan laki-laki. Dalam penelitian yang dilakukan di murid Taman Kanak-kanak Kota Sukabumi ditemukan hal yang berbeda dimana subjek dengan makanan katering lebih banyak perempuan, sedang yang tanpa katering lebih banyak laki-laki (5). Jumlah subjek dengan pengetahuan gizi cukup dan baik, hampir sama banyak untuk kedua kelompok. Subjek yang memiliki ibu yang tidak bekerja lebih banyak yang membawa bekal. Subjek yang mempunyai ibu dengan pengetahuan gizi cukup dan baik lebih banyak yang membawa makanan bekal dari rumah.

\section{Besar Porsi Sayur dan Buah}

Besar porsi sayur dan buah yang tersedia pada makanan bekal dan makanan katering sangat bervariasi. Sebagian besar kebutuhan serat diperoleh dari sayur dan buah. Kebutuhan serat anak usia 9-10 tahun antara 26-30 gr perhari (6). Dibandingkan dengan
Pedoman Gizi Seimbang (PGS) 2014 hasilnya dapat dilihat pada Table 1

Dari Tabel 1 dapat diketahui besar porsi sayur yang dibawa sebagai makanan bekal bervariasi dari paling sedikit 0 gr (tidak membawa sayur) dan paling banyak $81 \mathrm{gr}$, sedangkan besar porsi sayur yang disediakan pada makanan katering paling sedikit $17 \mathrm{gr}$ dan paling banyak 41 gr. Walaupun pihak katering setiap hari menyediakan sayuran namun besar porsinya masih kurang dari kebutuhan yaitu 75 gr perporsi tiap kali makan

Besar porsi buah pada makanan bekal bervariasi dari 0 gr (tidak membawa buah) dan paling banyak 100 gr. Besar porsi buah pada makanan katering bervariasi dari paling sedikit 0 gr (tidak diberi buah) dan paling banyak 50 gr.

Tabel 1. Distribusi frekuensi besar porsi sayur dan buah pada makanan bekal dan makanan katering dibandingkan dengan PGS 2014

\begin{tabular}{lcccc}
\hline \multicolumn{1}{c}{$\begin{array}{c}\text { Besar porsi } \\
\text { sayur dan buah }\end{array}$} & \multicolumn{2}{c}{$\begin{array}{c}\text { Makanan } \\
\text { bekal }\end{array}$} & \multicolumn{2}{c}{$\begin{array}{c}\text { Makanan } \\
\text { katering }\end{array}$} \\
\cline { 2 - 5 } & $\mathrm{n}$ & $\%$ & $\mathrm{n}$ & $\%$ \\
\hline Porsi sayur & & & & \\
1. Sesuai & 1 & 2.8 & 0 & 0 \\
2. Tidak sesuai & 35 & 97.2 & 36 & 100 \\
\hline Porsi buah & & & & \\
1. Sesuai & 5 & 13.9 & 19 & 50 \\
2. Tidak sesuai & 31 & 86.1 & 17 & 50 \\
\hline Jumlah & 36 & 100 & 36 & 100 \\
\hline
\end{tabular}

Kebanyakan subjek yang konsumsi sayur dan buahnya tinggi, mempunyai ibu dengan Pendidikan tinggi juga. Hal ini sejalan atau dengan penelitian pada anak usia sekolah di Kota Bogor (7) dimana ada kecenderungan makin tinggi tingkat pendidikan ibu makin baik konsumsi sayuran dan buahnya. 
Sebagian besar responden yang membawa makanan bekal dan mendapat makanan katering tidak mendapat porsi sayur dan buah yang sesuai kecukupan yang dianjurkan. Dari hasil observasi, jenis sayuran yang di bawa sebagai makanan bekal adalah jamur, tauge, sawi, buncis dan wortel dengan teknik pemasakan ditumis dan berkuah/ sop. Sedangkan jenis sayur yang digunakan oleh katering adalah wortel, buncis, kol, sawi dan daun singkong, dengan jenis masakan tumisan dan berkuah seperti sayur sop dan gulai daun singkong. Bekal buah yang di bawa subjek adalah pepaya dan pisang, sedangkan yang disediakan oleh katering lebih bervariasi yaitu pisang, papaya, semangka dan melon, semuanya tergolong buah tahunan. Untuk besar porsi buah, makanan katering masih lebih baik dibanding makanan bekal yaitu dimana buah yang disajikan 50\% sudah mencapai besar porsi yang cukup.

Penelitian tentang konsumsi sayur pada anak di SDI Al-Muslim dan SDIT AlHidayah, menunjukkan jenis sayuran yang sering dikonsumsi adalah wortel, bayam dan kangkung. Jenis buah tahunan yang sering dikonsumsi adalah pepaya dan pisang (8). Penelitian lain di 5 panti asuhan di Denpasar menunjukkan hasil rata-rata semua sampel mengkomsumsi sayuran seperti bayam, kol, kangkung, buncis, kacang panjang, dan wortel dengan frekuensi 2-4 kali dalam seminggu. Sedangkan frekuensi konsumsi buah-buahan hanya 1-2 seminggu (4). Hasil analisis data Riskesdas tentang faktor risiko obesitas anak usia 5-15 tahun pada tahun 2007 bila dikategorikan menurut standar PUGS (Pedoman Umum Gizi Seimbang) memperlihatkan hasil hanya $9,8 \%$ yang mengonsumsi sayur $>3$ porsi/hari,sedangkan mengonsumsi buah $>3$ porsi/hari hanya $7,6 \%$ (3). Penelitian Farris menemukan kualitas kandungan gizi makanan bekal lebih rendah dibanding makanan yang disediakan di sekolah (9).

Makanan bekal yang dibawa dari rumah maupun makanan katering hendaknya berfungsi sebagai alat penyuluhan bagi anak untuk terbiasa dengan pola makanan sehat termasuk konsumsi sayur dan buah. Keterbatasan waktu untuk menyediakan bekal sayur dan buah yang sesuai besar porsi dan bervariasi teknik memasaknya merupakan salah satu alasan kenapa makanan bekal sayuran dan buah tidak cukup dan tidak bervariasi.

\section{Asupan Sayur dan Buah}

Asupan sayur pada responden yang membawa makanan bekal dan makanan katering sebagian besar tidak sesuai dengan kecukupan. Bila dibandingkan dengan PGS 2014, maka hasil dapat dilihat pada Table 2 dimana asupan sayur pada makanan bekal bervariasi dari 0 gr - 44 gr, sedangkan asupan sayur pada makanan katering bervariasi

Tabel 2 Distribusi frekuensi perbedaan asupan sayur dan buah pada makanan bekal dan makanan katering dibandingkan dengan PGS 2014

\begin{tabular}{|c|c|c|c|c|}
\hline \multirow{2}{*}{$\begin{array}{l}\text { Asupan sayur } \\
\text { dan buah }\end{array}$} & \multicolumn{2}{|c|}{$\begin{array}{c}\text { Makanan } \\
\text { Bekal }\end{array}$} & \multicolumn{2}{|c|}{$\begin{array}{l}\text { Makanan } \\
\text { Katering }\end{array}$} \\
\hline & $\mathrm{n}$ & $\%$ & $\mathrm{n}$ & $\%$ \\
\hline Asupan sayur & & & & \\
\hline 1. Sesuai & 1 & 2,8 & 0 & 0,0 \\
\hline $\begin{array}{ll}\text { 2. } & \text { Tidak } \\
& \text { Sesuai }\end{array}$ & 35 & 97.2 & 36 & 100,0 \\
\hline Jumlah & 36 & 100,0 & 36 & 100,0 \\
\hline Asupan buah & & & & \\
\hline 1. Sesuai & 5 & 13,9 & 15 & 41,7 \\
\hline $\begin{array}{ll}\text { 2. } & \text { Tidak } \\
& \text { Sesuai } \\
\end{array}$ & 31 & 86,1 & 21 & 58,3 \\
\hline Jumlah & 36 & 100,0 & 36 & 100,0 \\
\hline
\end{tabular}

dari 0 - 41 gram. Asupan buah pada responden yang membawa makanan bekal dan makanan katering sebagian besar tidak sesuai dengan kecukupan. Bila dilihat dari responden yang mengkonsumsi sayuran dan buah dari makanan bekal, maka hanya 13 orang responden yang membawa bekal \begin{tabular}{l|l} 
Anggie Maramis Sarahita \& Irfanny Anwar & 4
\end{tabular} 
sayuran, dengan rata-rata asupan 32.1 gr, dan 5 orang responden yang membawa buah dengan rata-rata asupan 73.4 gr. Responden yang mengkonsumsi sayuran dari makanan katering sejumlah 15 orang dengan rata-rata asupan 19 gram, dan ada 32 orang responden yang mengkonsumsi buah dari makanan katering rata-rata 24 gram.

Ketersediaan sayuran dan jenis masakan pada makanan bekal dan makanan katering serta suhu makanan saat dihidangkan menjadi salah satu alasan kenapa asupan sayuran baik pada makanan bekal maupun makanan katering tidak sesuai kebutuhan. Makanan bekal yang disiapkan dari pagi membuat suhu makanan sudah dingin, begitu juga makanan katering juga disiapkan jauh sebelum waktu makan. Bentuk dan warna makanan juga akan mengalami perubahan apabila di masak dari pagi dan disimpan dalam keadaan tertutup. Kebiasaan mengkonsumsi sayur dan buah yang lebih rendah dari anjuran PGS juga terjadi pada siswa SMA, yaitu masing-masing dibawah anjuran 200 gr/ hari dan 300 gr sehari. Sedangkan frekuensi sehari baik sayur maupun buah rata-rata $<2 \mathrm{x}$ perhari. (10). Keluarga berkontribusi sebagai lingkungan sosial utama bagi anak untuk belajar dan mendapat pengalaman positif tentang makanan sehat (11). Asupan sayur dan buah yang masih tidak sesuai dengan PGS juga ditemukan pada SDI Al-Muslim dan SDIT Al-Hidayah (8). Asupan sayur juga sangat dipengaruhi oleh citarasa sayuran. Sayuran yang bumbunya kurang dan teknis memasak kurang bervariasi dapat menurunkan selera makan anak.

Dari hasil penelitian ini dapat dilihat bahwa anak dari ibu dengan pendidikan tinggi, lebih banyak mengkonsumsi sayur dan buah dibanding anak dari ibu dengan pendidikan rendah. Hal ini dibuktikan juga dalam penelitian di dua SD di daerah Bogor yaitu terdapat hubungan yang signifikan positif antara pendidikan ibu dengan konsumsi buah dan sayur subjek, yaitu semakin tinggi tingkat Pendidikan ibu maka konsumsi buah dan sayur pada subjek cenderung akan semakin baik (7). Dalam penelitian tentang pentingnya sayuran, diperoleh hasil bahwa peningkatan pengetahuan diharapkan akan mengubah sikap dan tindakan dalam mengkonsumsi sayuran sehari-hari (12)

Sebagian besar subjek yang membawa makanan bekal dan mendapat makanan katering tidak mendapat asupan sayur dan buah yang sesuai kecukupan yang dianjurkan. Namun untuk asupan buah secara rata-rata makanan katering masih lebih baik dibanding makanan bekal yaitu masing-masing $41.7 \%$ dan $13.9 \%$.

Hasil uji beda antara besar porsi serta asupan sayur dan buah pada makanan bekal dan makanan katering terlihat standar deviasi lebih besar dari nilai rata-rata. Hal ini disebabkan karena data besar porsi dan asupan sayuran dan buah baik pada makanan bekal maupun makanan katering sangat bervariasi.

Dari Tabel 3, rata-rata besar porsi sayur pada makanan bekal adalah 11.7 gram dengan standar deviasi 16.0 gram, sedangkan untuk makanan katering rata-rata besar porsi sayur adalah 22.7 gram dengan standar deviasi 5.6 gram. Hasil uji statistik didapatkan nilai

Tabel 3. Distribusi perbedaan besar porsi sayur yang disajikan pada makanan bekal dan makanan katering

\begin{tabular}{|c|c|c|c|c|c|}
\hline Variabel & $\mathrm{n}$ & Mean & SD & $\mathrm{t}$ & $\begin{array}{c}\mathrm{P} \\
\text { value }\end{array}$ \\
\hline Makanan & & & & \multirow[b]{3}{*}{3,9} & \multirow[b]{3}{*}{0,00} \\
\hline & 36 & 11,7 & 16,0 & & \\
\hline $\begin{array}{l}\text { Makanan } \\
\text { Katering }\end{array}$ & 36 & 22,7 & 5,6 & & \\
\hline
\end{tabular}

$\mathrm{P}=0.000$, berarti pada alpha $5 \%$ terlihat ada perbedaan antara besar porsi sayur pada makanan bekal dan makanan katering. Dapat 
dilihat bahwa besar porsi sayur pada makanan katering lebih baik bila dibandingkan dengan makanan bekal.

Dari Tabel 4 diketahui rata-rata besar porsi buah pada makanan bekal adalah 10.2 gram dengan standar deviasi 27.0 gram, sedangkan untuk makanan katering rata-rata besar porsi buah adalah 25.0 gram dengan standar deviasi 25.4 gram. Hasil uji statistik didapatkan nilai $\mathrm{P}=0.019$, berarti pada alpha $5 \%$ terlihat ada

Tabel 4. Distribusi perbedaan besar porsi buah yang disajikan pada makanan bekal dan makanan katering

\begin{tabular}{lccccc}
\hline Variabel & $\mathrm{n}$ & Mean & $\mathrm{SD}$ & $\mathrm{t}$ & $\begin{array}{c}\mathrm{P} \\
\text { value }\end{array}$ \\
\hline $\begin{array}{l}\text { Makanan } \\
\text { Bekal }\end{array}$ & 36 & 10,2 & 27,0 & & \\
\cline { 1 - 3 } $\begin{array}{l}\text { Makanan } \\
\text { Katering }\end{array}$ & 36 & 25,0 & 25,4 & & 0,019 \\
\hline
\end{tabular}

perbedaan antara besar porsi buah pada makanan bekal dan makanan katering, yaitu besar porsi buah pada makanan katering lebih baik bila dibandingkan dengan makanan bekal. Dari hasil penelitian Farris dikatakan, dilihat dari menu yang disajikan, sayur dan buah dari makanan sekolah lebih tinggi frekuensinya sehingga tingkat keterpaparan dengan sayur dan buah lebih tinggi dibanding anak yang membawa bekal. (9). Semakin sering anak-anak melihat sayur dan buah pada makanan siangnya, keinginannya untuk mencoba semakin besar.

Dari Tabel 5 rata-rata asupan sayur pada makanan bekal adalah 9.9 gram dengan standar deviasi 15.1 gram, sedangkan untuk makanan katering rata-rata asupan sayur adalah 20.6 gram dengan standar deviasi 9.1 gram. Hasil uji statistik didapatkan nilai $\mathrm{P}=0,001$, berarti pada alpha $5 \%$ terlihat ada perbedaan antara rata-rata asupan sayur pada makanan bekal dan makanan katering. Dapat dilihat bahwa asupan sayur pada makanan
Tabel 5. Distribusi perbedaan asupan sayur yang dikonsumsi pada makanan bekal dan makanan katering

\begin{tabular}{cccccc}
\hline Variabeln & & Mean & SD & $\mathrm{t}$ & $\begin{array}{c}\mathrm{P} \\
\text { value }\end{array}$ \\
\cline { 1 - 3 } $\begin{array}{c}\text { Makanan } \\
\text { Bekal }\end{array}$ & 36 & 9,9 & 15,1 & & \\
\cline { 1 - 3 } $\begin{array}{c}\text { Makanan } \\
\text { Katering }\end{array}$ & 36 & $\begin{array}{c}20, \\
6\end{array}$ & 9,1 & & 0,001 \\
\hline
\end{tabular}

katering lebih baik bila dibandingkan dengan makanan bekal.

Perbedaan asupan buah yang dikonsumsi pada makanan bekal dan makanan catering dapat dilihat pada Tabel 6

Tabel 6. Distribusi perbedaan asupan buah yang dikonsumsi pada makanan bekal dan makanan katering

\begin{tabular}{lccccc}
\hline Variabel & $\mathrm{n}$ & Mean & SD & $\mathrm{t}$ & $\mathrm{P}$ \\
\hline $\begin{array}{l}\text { Makanan } \\
\text { Bekal }\end{array}$ & 36 & 10,1 & 27,0 & & \\
\cline { 1 - 3 } $\begin{array}{l}\text { Makanan } \\
\text { Katering }\end{array}$ & 36 & 20,8 & 25,0 & & 0,087 \\
\hline
\end{tabular}

Dari Tabel 6 hasil uji statistik didapatkan nilai $\mathrm{P}=0.087$, berarti pada alpha $5 \%$ terlihat tidak ada perbedaan antara asupan buah pada makanan bekal dan makanan katering. Namun dari rata-rata asupan dapat dilihat bahwa asupan buah pada makanan katering lebih baik dibandingkan dengan makanan bekal.

Dapat dikatakan sebagian besar anak kurang menyukai sayuran. Dalam penelitian pada anak prasekolah ditemukan bahwa alasan tidak mengkonsumsi sayuran oleh karena sayuran rasanya pahit. Sebagian subjek tidak mengkonsumsi sayuran karena orang tua yang menganggap tabu beberapa \begin{tabular}{l|l} 
Anggie Maramis Sarahita \& Irfanny Anwar & 6
\end{tabular} 
jenis sayuran sehingga melarang anak mengkonsumsi sayuran tersebut. sedangkan alasan tidak mengkonsumsi buah adalah karena tidak menyukai beberapa jenis buah (13)

Penelitian yang dilakukan pada siswa SD di Makassar menujukkan bahwa edukasi gizi tidak meningkatkan asupan gizi (14). Namun pengaruh lingkungan dan teman-teman sangat besar terhadap asupan sayur dan buah (11). Apabila banyak teman yang menyukai sayur dan buah diharapkan akan mempengaruhi asupan sayur dan buah pada teman lainnya

\section{SIMPULAN DAN SARAN}

Besar porsi sayur dan buah makanan bekal yang dibawa dari rumah dan makanan yang disediakan katering di sekolah keduanya belum mencukupi kebutuhan sesuai PGS 2014, namun besar porsi makanan katering masih lebih baik dibanding makanan bekal. Asupan sayur pada kedua nya juga masih kurang, untuk asupan buah dengan katagori sesuai lebih banyak diperoleh oleh subjek yang mendapat makanan katering. Hasil uji statistik menunjukkan ada perbedaan antara besar porsi sayur dan buah pada makanan bekal dan makanan katering, ada perbedaan antara asupan sayur pada makanan bekal dan makanan katering, serta tidak ada perbedaan antara asupan buah pada makanan bekal dan makanan katering.

Disarankan agar pihak sekolah bekerjasama dengan pihak orang tua dan katering dalam hal menyusun menu seimbang bagi anaknya. Pihak orang tua dan pihak katering perlu diberi edukasi agar menambahkan sayur dan buah kedalam menu makanan anak setiap hari dan memodifikasi masakan sayur agar anak menyukai citarasanya dan kelak akan menjadikan sayur dan buah bagian penting dalam hidangannya.

Perlu penelitian lanjutan tentang besar porsi serta asupan sayur dan buah setelah dilakukan penyuluhan dan konseling kepada orang tua dan pihak katering

\section{DAFTAR PUSTAKA}

1. Kementerian Kesehatan RI. Pedoman gizi seimbang 2014.

2. Badan Penelitian dan Pengembangan Kesehatan Kementerian Kesehatan RI. Riset Kesehatan Dasar 2013. 2013

3. Ayu R, Sartika D. Faktor resiko obesitas pada anak 5-15 tahun di Indonesia. Makara. 2011;15(1):37-43.

4. Melisa L, Dewi, Sutiari NKI, Wulandari LPL. Status anemia gizi besi dan konsumsi zat gizi pada anak usia sekolah di lima panti asuhan di kota denpasar. Indones J Public Heal. 2012;1(1):35-42.

5. Nurhidayati VA, Martianto D, Sinaga T. Energi dan zat gizi dalam penyelenggaraan makanan di Taman Kanak-kanak dan perbandingannya terhadap subjek tanpa penyelenggaraan makanan. J Gizi Pangan. 2017;12(1):6978.

6. Kementerian Kesehatan RI. Permenkes RI No 75 tahun 2013 tentang AKG yang dianjurkan bagi Bangsa Indonesia. 2013.

7. Mohammad A, Madanijah S. Konsumsi buah dan sayur anak usia sekolah dasar di bogor.J Gizi Pangan.2015;10(1):71-6

8. Ronitawati P, Setiawan B, Sinaga $T$. Analisis Konsumsi Buah dan Sayur pada Model Sistem Penyelenggaraan Makanan di Sekolah Dasar.MKMI.2016;12(1):3540.

9. Farris AR, Misyak S, Duffey KJ, Davis GC, Hosig K, Atzaba-poria N, et al. Nutritional Comparison of Packed and School Lunches in Pre-Kindergarten and Kindergarten Children Following the Implementation of the 2012 - 2013 National School Lunch Program Standards Nutritional Profile of Packed. J Nutr Educ Behav [Internet]. 2014;46(6):621-6. Available from: http:// dx.doi.org/10.1016/j.jneb.2014.07.007

10. Ivo G. Konsumsi Sayur dan Buah pada Siswa SMA Negeri 1 Pekanbaru. J

Anggie Maramis Sarahita \& Irfanny Anwar $\mid 7$ 
Precure. 2013;1(April):50-7.

11. Dewi J. Analisis Konsumsi Buah dan

Sayur pada Model Sistem

Penyelenggaraan Makanan di Sekolah

Dasar. Calyptra, J Ilm Mhs Univ

Surabaya. 2013;2(1):1-17.

12. Ichsan B, Wibowo BH, Sidiq MN. Penyuluhan Pentingnya Sayuran bagi anak-anak di TK Aisyiyah Kwadungan, Trowangsan, Malangjiwan, Colomadu, Karang Anyar, Jawa Tengah. Warta. 2015;18(1):29-35.

13. Khurilín ML, Indrawati V. Faktor-faktor yang berhubungan dengan konsumsi ikan, sayur dan buah pada anak usia prasekolah di TK LPII, Desa Sawotratap, kecamatan Gedangan, Kabupaten Sidoardjo. e-journal boga. 2015;4(2):416.

14. Thasim S, Syam A, Najamuddin U. Pengaruh edukasi Gizi terhadap perubahan pengetahuan dan asupan zat gizi pada anak gizi lebih di SDN Sudirman I Makassat tahun 2013. J Unhas. 2013;1-14. 